\title{
The Innovative Thinking on the Teaching of Computer Science and Technology in Big Data Times
}

\author{
Zhihui Liu \\ Xi’an International University, Xi’an Shaanxi 710077
}

Keywords: Big Data Times; Computer Science and Technology; Teaching; Innovative Thinking

\begin{abstract}
The big data not only provides a platform for the development and studying of computer science and technology, but also the unlimited supports on resources and data. Therefore, on the base which is convenient, and which is provided by collection, description, transform, storage, index, and analyzing relevant data in big data times, it can effectively improve the studying efficiency of the students whose major are computer science and technology by innovating the teaching model and designing the targeted teaching contents, and then improve the overall teaching quality of the computer science

The traditional teaching of computer science and technology has some one-sided features: it mainly targets the limited data and segments in teaching, teachers often can only teach the key knowledge in the limited lessons so that ignore a lot of related information which need the students to study by themselves. But, most of the students are lack of self-learning ability. As the development of big data times, it provides the opportunity for solving this problem. What's more, as the development of Internet of things and the cloud computing, colleges can get unlimited data by lots of methods, so as to acquire knowledge by these data, and then carry out the teaching plans by combining these data with their specific teaching outlines.
\end{abstract}

\section{Conception of Big Data Times}

The big data is a wide conception which contains a lot of contents, most of people think that it is a kind of technology or a kind of product, but this is a wrong understanding. The big data times are the times that the conception of big data has been accepted by the public; it becomes popular; and it is developing quickly. It is another hot topic after cloud computing and Internet of things. Mentioning the big data, lots of people would associate it with digital technique and the massive database, but it is intrinsically different with the traditional massive database, there are still many disputes on the definition of it. In 2008, the Science defines the big data that----It represent the progress of human cognitive process, it is this kind of data that the scale of its data set could not get, administrate, and deal with by the present techniques, methods and theories in a durable period of time $^{[1]}$. As the development of big data, more and more scholars and researchers have made new definitions of it. By Baidu Searcher, the definition of big data is that----big data, or massive data, its scale is too large to administrate, deal with and sort out by present software tools in appropriate time for providing helpful information to enterprises' managements and decision-makings ${ }^{[2]}$, its structure is shown as chart 1 below. Anyhow, the conception of big data, its coverage is very extensive, although it is closely linked with the computer, even it comes from the processing capability of computer, but in fact the data size of the big data is huger than the data size that is larger than any computer could process. 


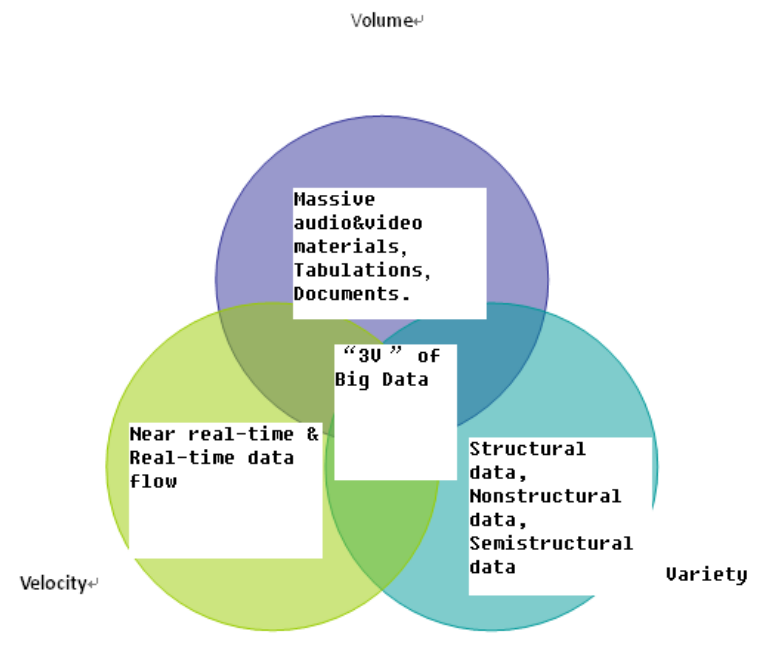

Fig.1. Definition of Big Data

\section{Innovative Advantages of Teaching on Computer Science and Technology in Big Data Times}

In big data times, the innovative advantages of teaching on computer science and technology are mainly as below: (1) Massive Data Resources. In big data times, every kind of teaching could search and integrate the massive teaching resources; it could break the limitation of lessons and textbooks, and bring new blood into teaching activities. (2) Network Advantages. In network, there are many courses that are related to computer science and technology, the students could purposively choose the resources which could advance their academic records and enforce their specialized skills. (3) Reformations of the New Teaching Model. AS the rapid development of information technology and network, although the new teaching platforms and the second lessons have heavily impact the traditional teaching model, but they brings the opportunities for reforming and developing the new model of courses. (4) Stricter Requirements to Computer Talents in China. The requirements to computer talents are very strict in China. In present, all walks of life need to rely on the support of computer technology and network technology in order to keep its development and daily operation ${ }^{[3]}$.

\section{Innovative Design of Teaching Contents on Computer Science and Technology in Big Data Times.}

In big data times, the teaching contents of computer science and technology need to follow scientific principle. First, the teachers should analyze the curricular structure of computer science and technology, so as to make the specific decisions, and it is one of the necessary steps of curricular planning. Nowadays, as the rapid development of computer technology, the computer information system could be used for processing and managing the data accurately and efficiently in lots of fields, so, the space of development for computer is very wide. The design of teaching contents needs to be split the knowledge into segments according to the needs of teaching task, it needs to integrate the effective date with the advanced technologies, and then, combine these with the courses of information technology, so as to show the demand of knowledge structure about computer science at last. The teachers should enrich the previous teaching contents with technology elements of current times; realize the different demand between hardware studying and software studying, then to set up relevant courses purposively so as to ensure a scientific lesson. After the content design of the lessons, teachers should make sure the teaching planning, teaching objective, teaching task, in order to assess if the new teaching contents and its relevant application could achieve the expectant goals. 


\section{Teaching Strategies on Computer Science and Technology in Big Data Times.}

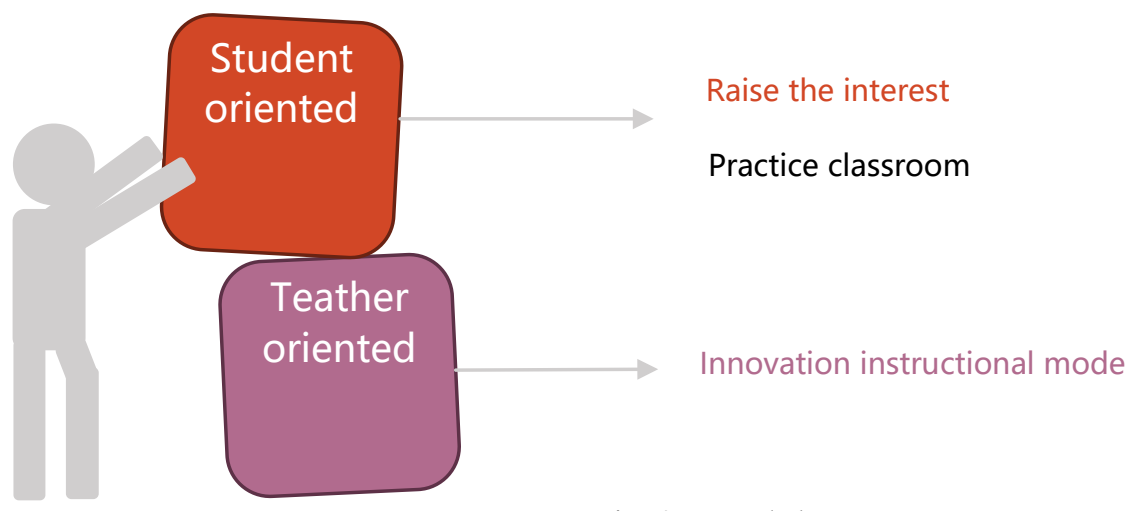

Fig.2. Model

To set up the major of computer science and technology, it is aim for training the talents who master the high and new technologies, and master every key knowledge points of computer as well. Although college study is the studying stage that is to consolidate the relevant knowledge, but there is still many basic knowledge that many students have not been touched ${ }^{[4]}$. To learn this basic knowledge, at the beginning, the students must study the relevant theories which are the premise of the practice, so some students who have lower basic abilities on this maybe feel it is hard to learn. If they keep this feeling for a long time, they must be lost heart. Therefore, the teachers must pay attention to bringing up the interests of their students; they should combine the theories and the practices at the beginning stage of the basic teaching, and connect the knowledge points with the posterior contents that will be practiced in the after teaching. Before the formal teaching, teachers could explain or demonstrate some interested tips or stories about computer, so as to bring up the students' desires of exploring this filed deeper. What' more, teachers should guide the students to have a deeper understanding about the specific conceptions, theories, basic methods, and applied fields; use some examples and cases for verifying the relevant theories in order to let the students know the wide prospect of this field; encourage the students to use their spare time to learn some relevant knowledge so as to expand their scope of knowledge; and teach the relevant new technologies and methods about the big data in lessons so as to accomplish that the students always are full of "passion" in the study of computer and put it into practices in the end, so as to improve the whole teaching quality ${ }^{[5]}$.

The launching and application of practical teaching are the necessary means in applied course teaching, it could makes the students put the theories into practice. For those students who want to have a try by themselves when the teacher is demonstrating, it is a good training opportunity. It changes students' study model from receiving the knowledge passively from their teachers into studying actively by themselves; these advantages above can help the students to solve the problems in practice by their basic knowledge. It not only can consolidate the knowledge of the students, but also their memory on the knowledge. In the process of practical teaching, teachers must make an effective curricular planning according to the key points of the teaching outline; help the students to decide the subject of programming; use the best of new teaching methods such as short video, multimedia teaching, etc to search and integrate the massive teaching resources in big data times; explain the cautions and the key techniques in practical programming carefully. To take the students as the most important part, teachers should encourage them and guide them to thinking actively, and give them some inspirations, so as to let they design the operation project by themselves, complete their report carefully, learn the relevant solutions, know to cooperation but cheating and idleness, finally, fulfill the practical courses. To these hard courses that require stronger technology, both the teachers and students could not accomplish at one stroke, these should be taught to the students from the elementary projects and then step by step. Teachers also should pay attention to the relativity between the different knowledge points and integrate the important theories and techniques into the hard courses so as to widen the students' knowledge by the simple projects, and the students could program the similar projects by themselves with the helps of their teachers ${ }^{[6]}$. For example, in computer science and technology, theory of database and application of Oracle are the 
two courses that require stronger specialty, the key points of the two courses' teaching should be these three parts----theory and principle, practice and operation, and curricular design. The teachers should take notice of the teaching procedure and guide the students to study step by step without teaching the textbook rigidly; avoid teaching so much but it is inefficient; present the teaching contents to the students by various forms such as pictures, cases, practical operations, so as to the students could understand the hard knowledge at the beginning. The technical terms could be simplified in necessary time, take a similar example that has the same condition with the teaching knowledge in order to make the students understand the basic theory.

Most of the computer teachers have many years teaching experiences, and have their own teaching systems as well, so their design of teaching contents are full of features; but, some teachers have taught different students with one teaching form for many years. As the progress of times and the reformation of education, all things on earth is changing, so the teachers should pay more attention to innovating the teaching methods, learn more cutting-edge knowledge about relevant theories and the development of technology, enrich their knowledge reserve, follow the development of the big data times, pay close attention to the need of industry, so as to optimize the teaching models and improve their teaching qualities. For example, CS2013, which is the newest system of course offering and its specialty and scientific feature follow the "Excellent Engineer Training Project", it adds lots of times elements to curricular design, adjusts and optimizes the curricular design and contents' design, makes the major to be characteristic by the big data and the training on computing thinking. The teachers should carry out teaching activities by following the development of times, let the students to know current developmental situation of computer science, the fields of computer's application, and the prospect of computer any time and any place, so as to encourage the desire of challenging and learn more knowledge by themselves. In the form of teaching, teachers should pay more attention to the basic and systematic teaching; teachers could not reduce the hours of basic core courses, ensure the connections between the contents must be no flaw, and ensure the integrity of the curricular contents. What's more, teachers should strengthen the training of computing thinking, increase the teaching contents which is base on data by using the relevant contents about computing thinking; and make the integrate the theories, the practices, and the big data tie closely, in order to give the students a overall cultivation and improve their comprehensive abilities on computer.

\section{Conclusion}

The major computer science and technology requires higher applied skills to the students, as a major that has higher practicability, in big data times, it requires the teachers to take the best of teaching advantages under the current times background; it requires to innovate the teaching methods and encourage students' leaning interest in the key knowledge teaching segments, such as programming language, operating system, database, software engineering and so on; it requires to set up more practical courses which could help the students transform the theory to applied abilities; and adjust the key courses purposively when teaching the basic knowledge, so as to achieve the teaching task that---- "Show Characteristics, Highlight Advantages".

\section{References}

[1]Zhou Yizhen, Discussion on the Comprehensive Reformation of Computer Science and Technology in Big Data Times[J]. Manager’ Journal, 2017, (11):357.

[2]Zou Huixia, Exploration and Researching on the Teaching Direction of Computer Science and Technology in Big Data Times[J]. TECHNOLOGY WIND, 2017,(06):92.

[3]Wang Minkang, Discussion on the Application of Protecting the Electronic Information by Computer Science----Starting From JD.COM and Tencent Uncovered the Information Revealing Event[J]. CHINA STRATEGIC EMERGING INDUSTRY, 2017,(12):5-6.

[4]Ge Minna, Exploration on College Basic Computer Teaching Reformation in Big Data Times[J]. 
Journal of Liaoning Economic Management Cadre Institute, 2016,(04):146-148.

[5]Tao Jun, Discussion on the Basic Feature and the Teaching Method about the Course of Data Encoding Technique[J]. E-Business Journal, 2014,(02):82+86.

[6]Jin Tao, Discussion on Specialty Teaching Reformation of Undergraduate Computer Science and Technology in Cloud Computing Times----Take Ordos College, Inner Mongolia University For Example[J]. Journal of Inner Mongolia Normal University (Educational Science), 2014,(01):90-92. 